\title{
LABORATORY EVALUATION OF THE DELTA Q TEST FOR DUCT LEAKAGE
}

\author{
JOHN W. ANDREWS
}

May 2003

Prepared for:

Office of Building Technologies

State and Community Programs

U.S. Department of Energy

Washington, DC 20585

Under Contract No. DE-AC02-98CH10886 


\section{DISCLAIMER}

This report was prepared as an account of work sponsored by an agency of the United States Government. Neither the United States Government nor any agency thereof, nor any employees, nor any of their contractors, subcontractors or their employees, makes any warranty, express or implied, or assumes any legal liability or responsibility for the accuracy, completeness, or any third party's use or the results of such use of any information, apparatus, product, or process disclosed, or represents that its use would not infringe privately owned rights. Reference herein to any specific commercial product, process, or service by trade name, trademark, manufacturer, or otherwise, does not necessarily constitute or imply its endorsement, recommendation, or favoring by the United States Government or any agency thereof or its contractors or subcontractors. The views and opinions of authors expressed herein do not necessarily state or reflect those of the United States Government or any agency thereof.

Available electronically at-

http://www.doe.gov/bridge

Available to U.S. Department of Energy and its contractors in paper from-

U.S. Department of Energy

Office of Scientific and Technical Information

P.O. Box 62

Oak Ridge, TN 37831

(423) 576-8401

Available to the public from-

U.S. Department of Commerce

National Technical Information Service

5285 Port Royal Road

Springfield, VA 22131

(703) $487-4650$

8 Printed on recycled paper 
Abstract........................................................................ vi

Introduction....................................................................

Delta Q Plus....................................................................

Laboratory Test Facility....................................................... $\quad 2$

Created Leaks.................................................................. 3

Overview of Results........................................................... 6

Detailed Test Results......................................................... 8

Leakage Cases A, B, and C (No Created Supply Leaks, 9

Return Leakage Varied).

Cases D, E, and F (Supply Disconnect, Return Leakage Varied).................. 11

Cases G, H, and I (Supply Trunk Leak, Return Leakage Varied)................ 12

Cases J, K, L, and M (Return Leaks Near Register)........................... 12

Estimating the True Leakage Pressures......................................... 14

Conclusions................................................................... 14

Acknowledgments............................................................ 15

References................................................................... 15

\section{LIST OF FIGURES}

Figure 1. Test Facility. Left: Register Box. Right: Ducts on Mezzanine 3

Figure 2. Error Sums for Fan Pressurization, Delta Q and Delta Q Plus 7

Figure 3. Leakage Rates to/from Outside for Cases A, C, D, and F 10

Figure 4. Leakage Rates to/from Outside for Cases B, E, G, H, and I 10

Figure 5. Leakage Rates to/from Outside for Cases J, K,L, and M 11 


\begin{abstract}
Using a residential-size duct system in a controlled laboratory setting, the repeatability and accuracy of the Delta $Q$ test for air leakage in residential duct systems have been measured. More than 100 Delta $Q$ tests were performed. These were compared with results using fan pressurization and also with results of a procedure (Delta $Q$ Plus) that uses leakage hole-size information to select the leakage pressures to be used in the Delta $Q$ algorithm. The average error in supply or return leakage for the fanpressurization test was $6.4 \%$ of system fan flow. For the Delta $Q$ test it was $3.4 \%$ of fan flow, while for Delta Q Plus it was $1.9 \%$ of fan flow.
\end{abstract}




\section{Introduction}

The current state of the art in duct leakage testing can be summarized as follows. The fan pressurization (duct blower) test measures the leakage hole size (or one of its proxies, such as CFM25). To convert this into a leakage rate, one has to guess an effective pressure at a typical leakage site and then pro-rate the CFM25 to an operating leakage rate assuming that the leakage flow is proportional to the 0.6 power of the pressure in the duct. This is less than satisfactory in that it can easily lead to errors in the $30 \%-50 \%$ range.

The Delta $Q$ test has been proposed as an alternative to fan pressurization. This test uses a series of blower-door measurements of the airflow required to pressurize or depressurize the house to a target pressure. The measurements are done in pairs, one with the heating/air-conditioning system fan off and the other with it on. These measurements are taken at ten values of the house pressure, ranging from $-25 \mathrm{~Pa}$ to $+25 \mathrm{~Pa}$ in $5-\mathrm{Pa}$ increments, omitting zero. At each house pressure, the difference between the airflow through the blower door with the system fan on and with it off is termed the $\Delta \mathrm{Q}$ for that pressure. Each $\Delta \mathrm{Q}$ provides the inputs to an equation whose two unknowns are the supply and return leakage rates between the ducts and the outside under normal operating conditions. These equations are solved simultaneously using a least-squares fit. A more complete description of the Delta Q test may be found in Walker et al. 2001.

As with fan pressurization, it is necessary in the Delta $Q$ test to guess supply and return leakage pressures. Although the Delta $Q$ test is usually less sensitive to the leakage pressures than the fan-pressurization test is, the results can still depend significantly on which values are chosen.

\section{Delta Q Plus}

The essence of Delta Q Plus is that knowledge of the effective leakage pressures is likely to produce more accurate results from the Delta $\mathrm{Q}$ test than simply assuming some standard values. Of course, it is highly desirable for this knowledge to be obtained in a way that is as economical of time, labor, and equipment as possible.

Two characteristics of the Delta Q test may enable this knowledge to be acquired. The first is the possibility of finding - encoded within the data required by the Delta $Q$ test itself-information leading to good estimates of the leakage pressures. This hope is encouraged by the fact that the Delta $Q$ test procedure is overconstrained by 8 degrees of freedom (10 equations, 2 unknowns). Although some preliminary work has been done in this direction (e.g., Andrews 2002), no definitive algorithm for extracting this information has been published. 
Alternatively, the Delta Q algorithm's relatively weak dependence on the leakage pressures may allow an iterative approach. This is described as follows, using the symbols $\mathrm{Q}_{\text {sleak }}$ and $\mathrm{Q}_{\text {reak }}$ to represent the supply and return leakage rates, respectively, to/from outside.

1. Perform the Delta $Q$ test to get initial estimates of $Q_{\text {steak }}$ and $Q_{\text {reak }}$, using half the plenum pressures as the initial estimates of the leakage pressures.

2. Perform a hole-size measurement to get sufficiently accurate values for the supplyand return-side leakage flow coefficients to/from outside: $\mathrm{C}_{\mathrm{s}}$ and $\mathrm{C}_{\mathrm{r}}$.

3. Use the pressure-flow relationship

$$
\mathrm{Q}=\mathrm{C} \Delta \mathrm{P}^{0.6}
$$

to obtain new values for the leakage pressures.

4. Insert these values into the Delta $Q$ algorithm to get new values of $Q_{\text {sleak }}$ and $Q_{\text {rleak }}$.

5. Return to Step 3, and keep iterating Steps 3 and 4 until convergence is obtained.

In applying this algorithm, it was found advisable to put upper and lower bounds on the leakage pressures. The need for a lower bound derives from the tendency of the Delta $Q$ algorithm to behave erratically when very small leakage pressures are assumed. The upper bound was deemed advisable to prevent the process from producing leakage pressures very much greater than the measured plenum pressure. In this analysis, the lower and upper bounds were set at $25 \%$ and $125 \%$ of the measured plenum pressure, respectively.

It was also found helpful, at each step of the iteration, to select, as the next value of a leakage pressure, the average of the one used in the previous step and the one indicated by the next application of the Delta Q algorithm. This almost eliminated "hunting" behavior in which the solution oscillates between two values. In all but two of the 107 Delta $Q$ tests that composed the sample, the process resulted in convergence within $1 \%$ in fewer than 10 iterations.

\section{Laboratory Test Facility}

The tests were performed in a thermal distribution test facility comprising an instrumented residential-size duct system located within a high-bay work space that can be opened to the outside. The supply duct system consists of a main trunk duct splitting into two branch ducts, with four runouts emerging from each branch. All the ducts are of sheetmetal construction, the trunk and branch ducts being rectangular and the runouts round. Most of the supply ducts are located on a mezzanine halfway between the floor and the ceiling of the high bay. The single return duct is of rectangular sheet metal. The duct surface area is $395 \mathrm{ft}^{2}$ on the supply side and $127 \mathrm{ft}^{2}$ on the return side. The supply-duct area equals the default value in ASHRAE Standard 152P (ASHRAE 2001) for a house with $1460 \mathrm{ft}^{2}$ of heated floor area.

The fan speed is continuously variable, with total airflow ranging from near zero to $\sim 1500 \mathrm{cfm}$. A True-Flow ${ }^{\mathrm{TM}}$ flow plate was left in the system at the return plenum. This 
allowed easy measurement of airflow to $\pm 2 \%$ (instead of $\pm 7 \%$ if the flow plate is inserted only when measuring airflow). The added pressure drop caused by the flow plate was treated as if it were caused by an elbow in the return duct system. The system flow rate was calculated from the flow-plate reading plus any leaks into the air handler between the flow plate and the system fan. Depending on what leaks were added to the system, this varied from $\sim 900$ to $\sim 1100 \mathrm{cfm}$.

The building envelope was simulated by an enclosure (the "register box"), roughly the size of a walk-in cooler (Figure 1). The supply registers are in the ceiling near one end of the register box, while the return register is near ground level, at the other end of the box. Envelope leakage was simulated by means of a $1 \mathrm{ft}$ square hole between the register box and the outside. The leakage measured by a blower door corresponded to a flow rate at $25 \mathrm{~Pa}$ (CFM25) averaging $\sim 900 \mathrm{cfm}$.

\section{Figure 1. Test Facility. Left: Register Box. Right: Ducts on Mezzanine.}
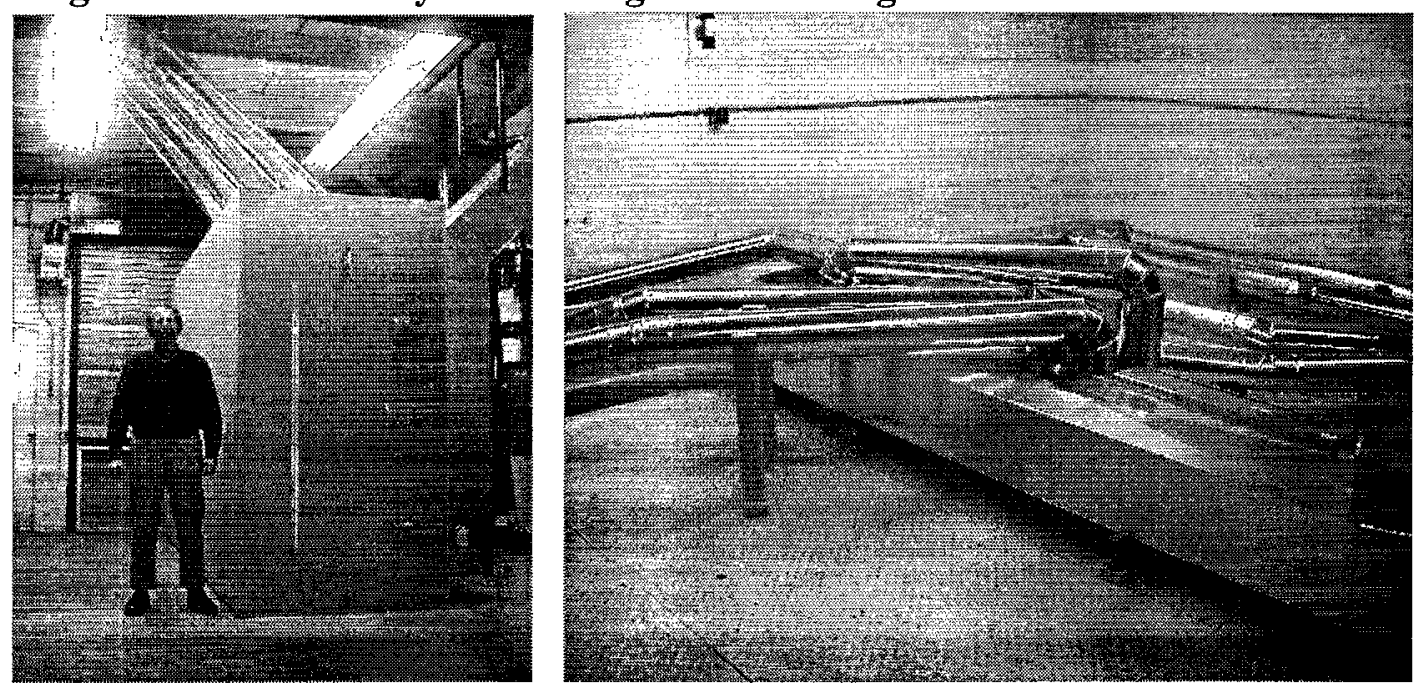

Within the high-bay enclosure, most of the supply duct system, the fan, and the control station are located on a mezzanine, while the register box, the last several feet of each supply runout, and the return intake are on the ground floor. Pressures were measured with static-pressure probes linked to a digital manometer. Airflow at the return plenum was measured using the abovementioned flow plate. Airflows through added leakage sites were measured in several ways as described below.

\section{Created Leaks}

The testing was begun with the duct system sealed as well as could be done by hand. The hole sizes in the supply and return sides of the duct system were then measured by fan pressurization. A special test was conducted in which two barriers were set in place, one at the usual location at the return plenum, and the other at the fan itself. This allowed the leakiness of the air handler upstream of the fan to be determined. The air handler CFM25 was subtracted from the measured supply-side CFM25 to give a true supply-side CFM25, 
which was then translated to a leakage rate assuming the leaks to be at one-half the plenum pressure. In estimating the return leakage, the portion of the air handler upstream of the fan was assumed to be at the return-plenum pressure, while the remainder of the return duct was assumed to be at one-half the plenum pressure.

The measured values for these baseline leaks were $19 \pm 10 \mathrm{cfm}$ on the supply side and $32 \pm 10 \mathrm{cfm}$ on the return side. The percentage uncertainties in these baseline leaks are relatively large, based as they are on hole-size measurements, but the absolute uncertainty is relatively small because the hole sizes are small. This baseline system was called Case A.

Twelve other cases were constructed by imposing various combinations of measurable leaks on the baseline system. Each of these "created leaks" was measured in situ using two different measurement techniques. The total leakage in each case was then determined by adding the created leak to the baseline leak, with the latter corrected for any change in the pressures in the duct system caused by adding the created leak. These corrections were always quite small, never more than $6 \mathrm{cfm}$. Uncertainties in the resulting leakages were determined by adding in quadrature the uncertainty in the baseline leakage to that in the created leak.

The types of leaks used in these experiments were as follows:

- $\quad$ Long supply disconnect. To create this leak, $30 \mathrm{ft}$ length of 10 " diameter flexible duct, ending in a $10 \mathrm{ft}$ long straight pipe, was run from one of the supply registers to the outside. Airflow through this duct was measured using: 1) a flow hood capable of measuring flows between 10 and $500 \mathrm{cfm}$; and 2) a hot-wire anemometer mounted inside the long straight pipe. The linear flow rate recorded by the hot-wire anemometer was calibrated to an overall volume flow rate using a duct blower.

- $\quad$ Supply trunk leak. One of the 7" diameter supply runouts comes off the main trunk and makes an immediate right-angle bend. This was replaced by a tee, onto the free end of which was inserted a $4 \mathrm{ft}$ length of open-ended duct. Airflow through this leak was measured in two ways: 1) the same flow hood described above; and 2) readings of a hot-wire anemometer averaged over the cross-sectional area of the short openended duct.

- Return leak at the plenum. An unpowered duct blower was attached to an opening in the return plenum. By placing different rings in the duct blower, leaks of various sizes could be created. In these tests, the two largest rings were used. Airflows through these leaks were measured in two ways: 1) with the duct blower as a flow meter, using the calibration curve supplied by the manufacturer; and 2) with the flow hood. 
- Return leak near the register. The unpowered duct blower was attached to a hole in the duct directly opposite the return register. As in the previous case, airflows were measured using the duct blower itself and also with the flow hood.

When the duct blower was combined with another measurement technique, the duct blower was treated as the primary source of data because its uncertainty was considered more reliably determined. In no case did this entail rejecting alternative measurements that differed by more than $7 \%$ from the duct-blower value. The one exception was in some of the return-leak-near-register cases, in which the flows were highly variable even though the fan was running at constant speed. In these cases it was decided to rely equally on the duct blower and the flow hood. When the duct blower could not be employed, the two methods that were used were weighted equally. Created leaks measured using the duct blower were estimated to have $\sim 5 \%$ uncertainty, in line with the manufacturer's estimate. (The maximum depressurization on the downstream side of the duct blower was less than $60 \mathrm{~Pa}$.) For leaks not measured with the duct blower, the major indicator of uncertainty was the difference in flows as measured using the different methods. The uncertainty in measured leakage averaged $\pm 15 \mathrm{cfm}$.

The use of created leaks raises the question of what exponent should be applied to the pressures in the Delta $Q$ equations. Usually a default value of 0.6 is used, consistent with what is typically found for a multitude of small leaks. However, when the bulk of the leakage flow is through one or two large metered openings, one would expect the actual exponent to be closer to 0.5 , which is the theoretical value for orifice flow. In these experiments, the exponent for Case A (pre-existing leaks only, no created leaks) was measured as 0.67 . Measured exponents for cases $B$ through $F$ were found to lie between 0.53 and 0.59. An analysis to separate out the effect of the pre-existing leaks in these cases found that the exponents for the created leaks did equal 0.50 (within 1\%). In view of the range of exponents measured for the whole duct, it was decided to use 0.55 as the exponent in all cases except $A$, where 0.60 was used for consistency with usual practice. That is, it was judged reasonable to adjust the exponent to allow for the special characteristics of the created leaks, but not for the pre-existing ones.

A study of the effect on the results of changing the exponent in the Delta $Q$ equations was performed. The results can be simply stated. First, increasing the exponent from 0.5 to 0.6 added $25 \%$, on average, to the sum of the supply and return leakage, and this fraction was quite uniform over most of the cases. Second, the difference between the supply and return leakage changed very little, only about a tenth as much on average as the sum of the two leakage values. What this means is that on a graph in which $\mathrm{Q}_{\text {sleak }}$ is plotted horizontally and $\mathrm{Q}_{\text {rleak }}$ is plotted vertically, changing the exponent will cause the data point to move along a line of slope +1 . Use is made of this result in the discussion of cases $G, H$, and I, below. 


\section{Overview of Results}

For each of the thirteen leakage cases (designated by the.letters A through $M$ ), three test methods were compared: fan pressurization, Delta $Q$, and Delta Q Plus. The accuracy of each test for a given case was represented in terms of an "error sum" defined as follows:

$$
\text { Error sum }=\mid \text { Qsleak,test }- \text { Qsleak, actual }|+| \text { Qrleak,test }- \text { Qrleak,actual } \mid
$$

Qsleak,test and Qrleak,test are the supply and return leakage values, respectively, from the test. Qsleak,actual and Qrleak,actual are the supply and return leakage values, respectively, obtained by combining the leakage of the baseline system with the independently measured created leaks, as discussed above.

It is important to emphasize that these error sums are not estimates of random experimental uncertainty. Instead, they are combined measures of the deviations of supply and return leakage (as reported by the duct leakage test) from independently measured values.

For leakage case A all three tests performed about equally well, with error sums as defined above of $\sim 25 \mathrm{cfm}$ (Figure 2). The system fan flow rate for case A was $910 \mathrm{cfm}$, so this represents an average error on each side of the duct system of $1.4 \%$ of system fan flow. In a typical house, this amount of error in the leakage measurement will produce an error in seasonal distribution efficiency (as calculated using ASHRAE Standard 152P) of $\sim 2 \%$ if the error is in the supply leakage and $\sim 1 \%$ if in return leakage. These low values illustrate the common observation that most leakage tests perform well enough if the ducts don't leak very much.

The situation for the cases with created leaks is more variable. As has been observed previously (Cummings et al. 2000, Francisco and Palmiter 2000a, 2000b), the accuracy of the fan-pressurization test depends strongly on whether an accurate value for the leakage pressure has been used. The present results are consistent with this. The most inaccurate fanpressurization results were obtained for cases where a large leakage hole was located at or near a plenum, where the actual leakage pressure was about twice the assumed value. In 8 of the 13 leakage cases, the Delta $\mathrm{Q}$ test was a distinct improvement over fan pressurization, while in 4 other cases there was not much difference in their accuracy. In only one case (Case G) did fan pressurization show a distinct advantage. 
Figure 2. Error Sums for Fan Pressurization, Delta $Q$ and Delta Q Plus

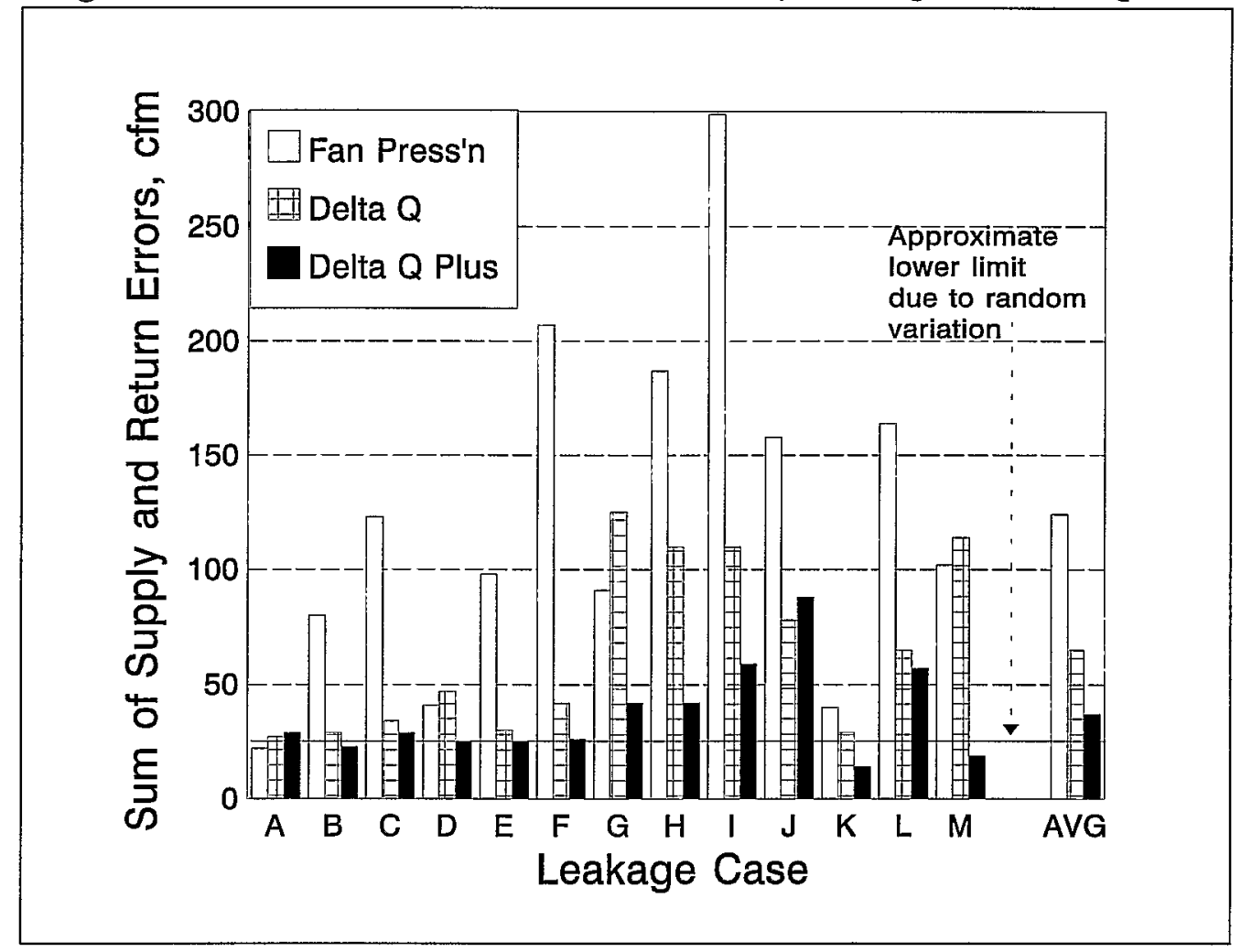

The repeatability of the Delta $Q$ test depends on the leakage of the building envelope. The greater the envelope leakage, the greater the variability of the Delta $Q$ results. The line drawn across Figure 2 at $25 \mathrm{cfm}$ represents the sum of the average standard deviations of supply and return leakage values reported by the Delta $Q$ test. This can be considered a rough average lower limit for the errors in the Delta Q (or Delta Q Plus) test for the particular envelope leakage used in these tests (CFM25 $\approx 900$ ). (The lower limit on random error can be reduced by running the Delta $\mathrm{Q}$ test more than once and averaging the results.) Any errors significantly above this line represent systematic biases that might be eliminated by improvements in the test procedure. Note that this treatment is approximate since the error sums might not be normally distributed.

The Delta Q Plus procedure - using information on the leakage hole size to "bootstrap" knowledge of the leakage pressure - provided significant benefit in most of the cases where the Delta $Q$ error sum was above the $25 \mathrm{cfm}$ minimum defined by random variation. Four cases in particular (G, H, I, and M) showed striking improvement, while several others showed smaller benefits.

One caveat should, however, be mentioned. It is possible that Delta Q Plus worked so well in these tests because most of the leakage was concentrated at a single pressure, 
which is what is assumed in the derivation of the Delta $Q$ equations. If the leaks were distributed throughout the duct, perhaps Delta Q Plus would not have reduced the errors as much as it did here.

The results can be summed up as follows. The average error in supply or return leakage for the fan-pressurization test was $6.4 \%$ of system fan flow. For the Delta $Q$ test it was $3.4 \%$ of fan flow, while for Delta Q Plus it was $1.9 \%$ of fan flow.

\section{Detailed Test Results}

The test results are shown in Figures 3-5, organized to avoid data overlap between cases. In these figures, each of which displays four or five of the thirteen leakage cases, the horizontal axis is the supply leakage rate to outside and the vertical axis is the return leakage rate from outside. For each leakage case, the independently measured ("actual") values of the supply and return leakage are indicated by a cross, the horizontal and vertical arms of which represent the estimated uncertainties in the leakage rates.

The eight-pointed asterisk associated with each leakage case is the result of a fanpressurization test, obtained as described above. Where the fan-pressurization data point is far from the actual values, a dotted line is used to connect the asterisk to the correct leakage case.

For each of the leakage cases, eight (in one case, 11 ) Delta $Q$ tests were performed. The X symbols represent the results of the Delta $Q$ tests. The size and shape of the "shotgun pattern" of these points is a measure of the repeatability of the Delta $Q$ test for the level of envelope leakage represented in this experiment. As predicted theoretically (Andrews 2000) the patterns tend to be elliptical rather than circular, with less variation in the difference between the two leakage rates than in their sum.

The Delta Q leakage rates were calculated assuming that the leakage pressures in the supply and return ducts were one-half the pressures measured at the supply and return plenums, respectively. Also, the actual plenum pressures (with respect to the "house") were used at each of the ten house pressures, in contrast to the traditional assumption that the plenum pressures remain constant throughout the test protocol. This was done because of a suggestion (Francisco and Palmiter 2001) that using constant house-to-duct pressures could bias the test. In all but 5 cases out of the 214 supply and return leakage values, the difference in leakage rates derived using the two options was less than $10 \mathrm{cfm}$.

The dark squares show the results of the Delta Q Plus procedure. The hole-size values needed for Delta Q Plus were obtained from the fan-pressurization measurements. 


\section{Leakage Cases A, B, and C (No Created Supply Leaks, Return Leakage Varied)}

These are found on Figures 3 and 4 . In each of these cases there is no added leakage on the supply side, so the actual supply leakage was $20 \pm 10 \mathrm{cfm}$. Return leakage is added at the plenum using an unpowered duct blower as a flow meter. Case $\mathrm{A}$ is the baseline, in which the best estimate of return leakage is the as-found value of $32 \pm 10 \mathrm{cfm}$. In Case B, Ring 2 was used on the duct blower, increasing the return leakage to $164 \pm 12 \mathrm{cfm}$, while in Case C, Ring 1 on the duct blower produced an actual return leakage rate of $297 \pm 17 \mathrm{cfm}$.

The Delta Q test did an excellent job of "seeing" the increase in return leakage, with average reported values for Cases $\mathrm{A}, \mathrm{B}$, and $\mathrm{C}$ of 58,172 , and $309 \mathrm{cfm}$, respectively. The value for Case $A$ is about two error bars high, while the Case $B$ and Case $C$ values are within the error bars.

On the supply side, there appears to be a systematic decrease in the reported leakage values in going from Case $\mathrm{A}$ to Case $\mathrm{C}$, even though the actual supply leakage remained the same (to within $2 \mathrm{cfm}$ ). This may be an example of the "crosstalk" phenomenon reported by Francisco and Palmiter (2001), in which a change in the leakage on one side of the duct system may affect the value reported by the Delta $Q$ test on the other side. In this case, the effect was not large, especially when one considers that the negative values found in Cases $B$ and $\mathrm{C}$ would be converted to zero in any practical application of the Delta $\mathrm{Q}$ test.

The fan-pressurization test, in contrast, did not do very well on the return leakage in Cases B and C. This was no surprise, since the created leaks were at the return plenum whereas the assumed leakage pressure is half the plenum pressure. If the measured CFM25 is instead converted to a value at the full plenum pressure, the fan-pressurization leakage values agree well with the measured ones, but of course this is not a fair test since in a real application one usually does not know where the leaks are.

When the Delta $Q$ Plus procedure was employed on these data, there was little change in Cases A and B, and modest improvement in Case C. All but one of the negative supply leakage values were eliminated from Case C. This removed the "crosstalk" effect noted above. 
Figure 3. Leakage Rates to/from Outside for Cases A, C, D, and F

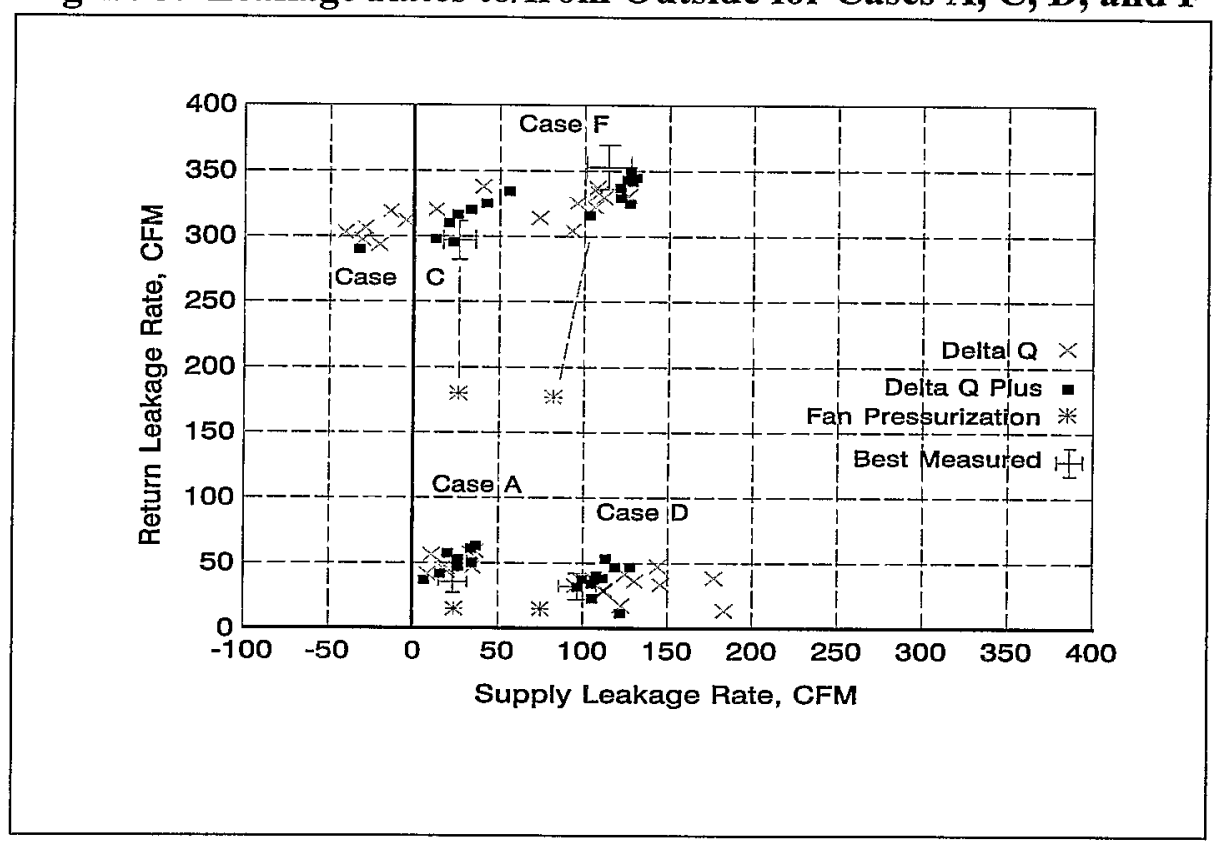

Figure 4. Leakage Rates to/from Outside for Cases B, E, G, H, and I

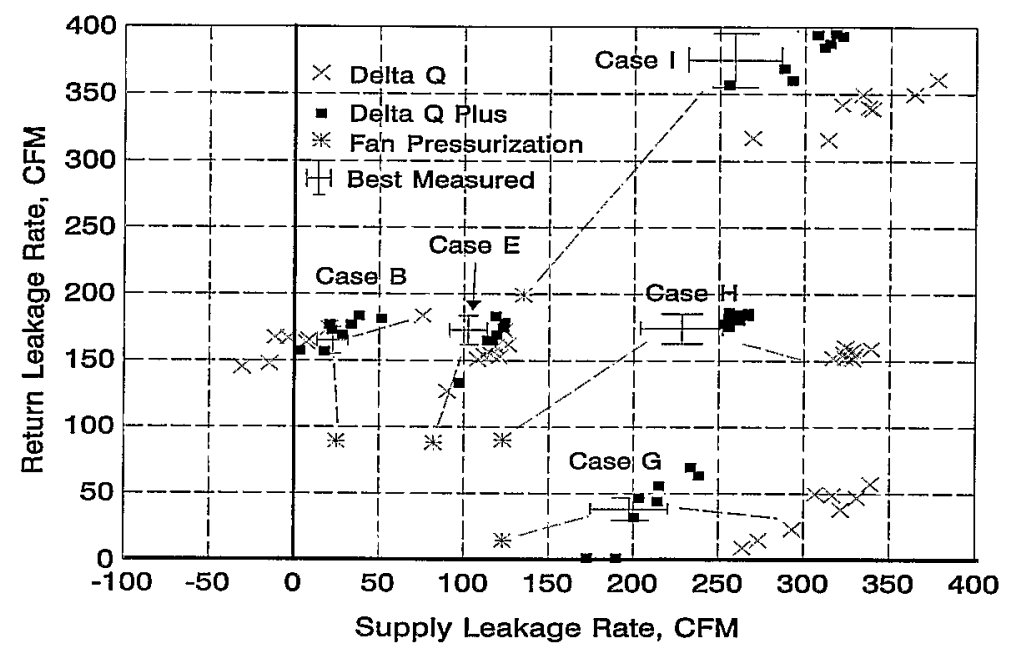


Figure 5. Leakage Rates to/from Outside for Cases J, K, $L$ and $M$

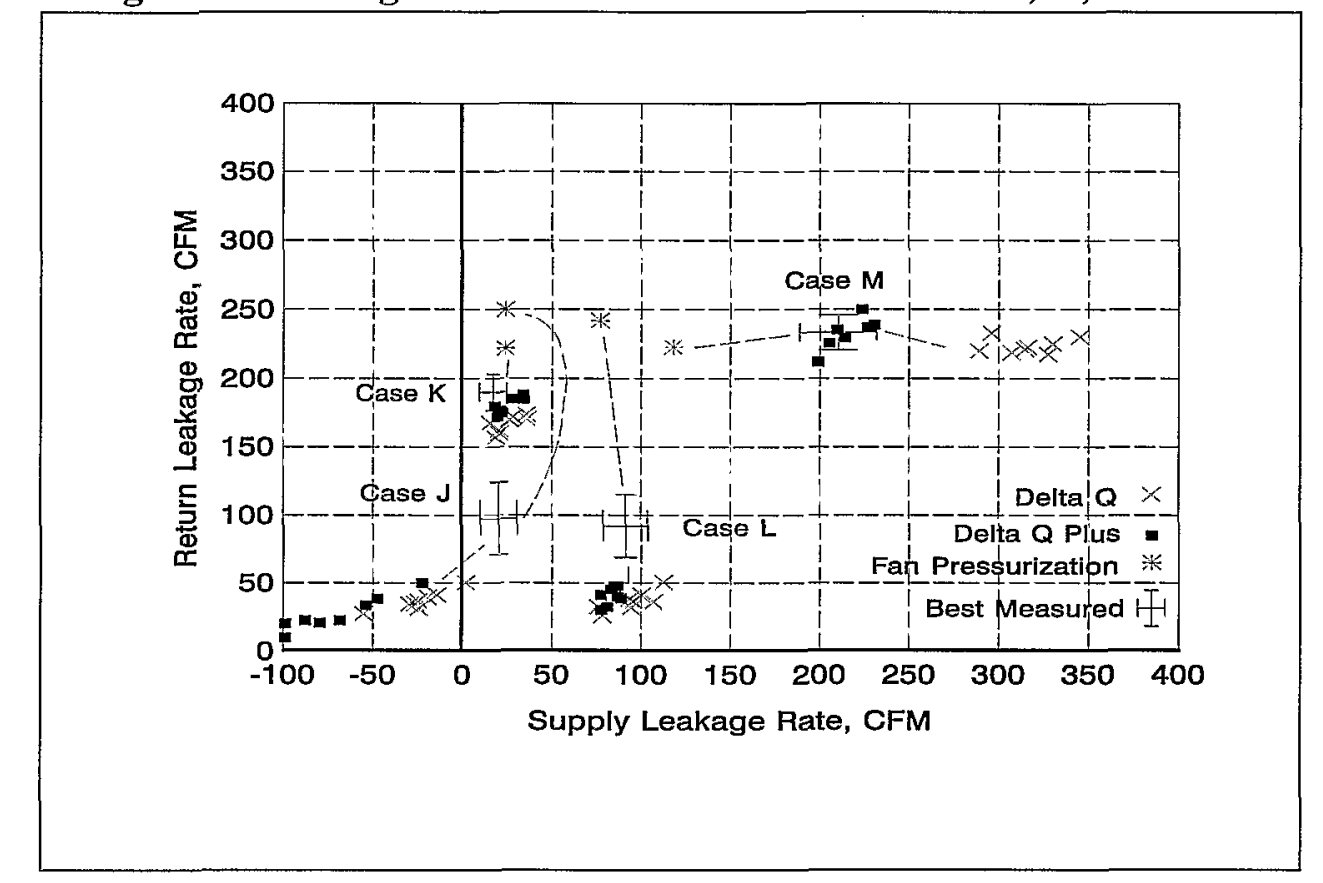

\section{Cases D, E, and F (Supply Disconnect, Return Leakage Varied)}

These cases have in common the addition of a leak on the supply side using the long disconnected duct. The cases differ among themselves in the same way as Cases A, B, and $\mathrm{C}$, namely that there are-respectively-zero, small, and large created leaks at the return plenum.

As in the first set of three cases, the Delta $Q$ test did a good job of finding the return leakage, reporting values that were on average within one (or for Case F, two) error bars of the measured value. On the supply side the results were mixed, with the Delta $\mathrm{Q}$ test overestimating supply leakage in Case D by three error bars (with quite a bit of scatter), coming within one error bar in Case $\mathrm{E}$, and underestimating by $\sim 2$ error bars in Case F. Again there is the systematic decrease in reported supply leakage in going from Case $\mathrm{D}$ to Case F, despite the fact that the measured supply leakage increased slightly. This appears to be another example, albeit a mild one, of the abovementioned "crosstalk" phenomenon.

The fan-pressurization test did about as good a job as the Delta $\mathrm{Q}$ test in finding the supply leakage in these cases, but on the return side it had the same level of inaccuracy as in Cases A, B, and C, presumably for the same reason.

The Delta Q Plus procedure gave modest improvement in the results for Cases $\mathrm{E}$ and F, but it is in Case D where the most significant effect was noted. Here the outlying supply leakages above $150 \mathrm{cfm}$ were eliminated, and although some overestimate of supply leakage remained, it was relatively small. As in Cases A, B, and C, the "crosstalk" effect went away. 


\section{Cases G, H, and I (Supply Trunk Leak, Return Leakage Varied)}

These cases have in common the addition of the supply-trunk leak, with return leakage varied in the same way as in the two previous groups of three. The ability of the Delta $\mathrm{Q}$ test to measure return leakage was nearly as good in these cases as in Cases D, E, and $F$. The average Delta $Q$ value for Case $G$ was almost exactly the same as the measured value, while for Cases $\mathrm{H}$ and I the reported value differed from the measured one by about two error bars. On the supply side, however, the Delta $\mathrm{Q}$ test was not nearly as successful, overestimating the leakage, on average, by $\sim 80 \mathrm{cfm}$.

From the earlier discussion of the effect of changing the exponent in the Delta $Q$ equations, one can note that in these three cases the measured data points lie well to the right and a little below the actual values. Since changing the exponent moves these points along a line of slope +1 (the " 45 degree line") one can see that revising the choice of exponent will not greatly improve the level of agreement here. A similar comment will apply to Case $M$ (discussed below).

The fan pressurization test was nearly correct when there was no created return leakage, but it significantly under-reported the leakage when there was. As in previous cases, the result is consistent with the fact that the created leak was at the plenum.

The Delta Q Plus procedure nearly eliminated the supply leakage overestimation in these cases, yielding points that lay in or near the boundaries described by the error bars. The supply leakage values reported by Delta Q Plus increased going from Case G to Case I, but this is a real effect as shown by the increase in measured leakage, and not "crosstalk."

\section{Cases J, K, L, and M (Return Leaks Near Register)}

These cases differ from all the previous ones in that return leakage is added near the register rather than at the plenum. In all these cases, the added return leak was a 7-inch hole cut into the return duct at a point directly opposite the register. That is, air coming into the return register must make an immediate 90-degree turn in order to go up toward the air handler. The added return leak was situated such that if this air didn't make the turn, it would go out the return leak. Not surprisingly, this placement of the leak gave rise to some interesting effects.

The unpowered duct blower was installed (with Ring 1 in place) on the outside of the duct directly against the leak site, so that all air entering the leak had first to go through the duct blower. This provided a convenient way to measure the airflow into the leak to be measured.

The simplest case conceptually is Case J. It had no created supply leak. When the system was operating, return leakage was found to fluctuate, with strong "puffs" of flow interspersed with equal periods of relatively low flow. These fluctuations were seen both 
with the duct blower and with the flow hood. This "chaotic" behavior was probably caused by impingement of the air entering from the register onto the leakage site. The variability of the flow is the reason for the large error bar on return leakage in Case J.

The Delta Q test underestimated both the supply and return leakage rates in Case J. On the supply side, in fact, the leakage rate almost always came out negative. The fanpressurization test, in contrast, vastly overestimated the return leakage rate, although it did quite well on the supply side. The overestimation of return leakage is ascribed to the same cause as its failure in other cases studied, namely that the actual leakage pressure (as indicated by a pressure tap just above the leakage site) was quite low, $\sim 10 \mathrm{~Pa}$ or one-sixth of the plenum pressure.

To investigate the nature of the leakage occurring at this site, a baffle was inserted into the return duct (Case K). The baffle was directly in front of the return leak and had the effect of a turning vane, forcing the air coming into the return duct to flow upward toward the air handler without impacting the leakage site. The leakage site was still in good communication with the rest of the duct, because the top edge of the baffle was located approximately 6 inches from the back of the return duct, leaving a 6-in. X 18-in. space for air to flow from the leak into the return duct.

Because of this good communication, fan pressurization gave about the same result for this case as for Case J. The actual leakage, however, was much higher for Case $\mathrm{K}$ than it was for Case $J$, and the agreement with the fan-pressurization result in Case $\mathrm{K}$ was actually good. This is probably due in part to the fact that the effective leakage pressure in Case $\mathrm{K}$ $(\sim 16 \mathrm{~Pa})$ was higher than that for Case J ( $10 \mathrm{~Pa})$. Probably of at least equal importance, however, is the dynamic effect of shielding the leakage site from impaction by air flowing into the return register.

It was as expected that fan pressurization gave nearly the same result for these two cases, but it was a pleasant surprise that the Delta Q test easily "saw" the difference. Its agreement with the measured value in Case $\mathrm{K}$ was quite good, though there was a slight underestimate of return leakage.

The Delta Q Plus procedure changed little in either of these cases. In Case J, the supply leakage values became more negative; however, since in a real application of either test negative values would be set equal to zero, this would not have made much difference.

Case $\mathrm{L}$ had the same kind of return leak as Case J, i.e., no baffle was installed, but in addition there was an added supply leak in the form of the long disconnected duct. The performance of all three tests was essentially in line with that on Cases $\mathrm{J}$ and $\mathrm{K}$, i.e., all tests did well enough on supply leakage and performed similarly to Case J on return leakage.

For Case M, the added supply leak was the one off the supply trunk, similar to Cases $\mathrm{G}, \mathrm{H}$, and I, while the return leak was the same as in Case $\mathrm{K}$ (the baffle was in place). The 
performance of all three tests on the supply side was similar to that in Cases $\mathrm{G}, \mathrm{H}$, and I, while their performance on return leakage was similar to that in Case K. The Delta Q Plus procedure again brought the supply leakage rate into line with the measured value.

The salient comment on these four cases is that fan pressurization did not "see" the difference between the return leaks with and without the baffle, whereas the Delta Q and Delta Q Plus tests did. This represents, in the author's view, a marked success for the Delta Q approach.

\section{Estimating the True Leakage Pressures}

As stated above, hole-size information used in Delta Q Plus was obtained from the fan-pressurization data obtained in the course of the experiments. This procedure is somewhat time-consuming and if required would reduce the attractiveness of Delta Q Plus to field practitioners. Simpler ways to measure hole size are being investigated, but these are beyond the scope of this paper.

As mentioned earlier, it is also possible that information on the leakage pressures can be extracted from the Delta $Q$ data. One way to do this could be by examining the shapes of the curve of $\Delta Q$ vs. house pressure. This is influenced by the leakage pressure (Andrews 2002). Another useful approach may be to seek values for the leakage pressures that minimize the root-mean-square error in the least-squares fit.

\section{Conclusions}

The salient findings of this study were summarized in Figure 2. The Delta $Q$ test for duct leakage performed well in these tests, with absolute errors averaging about half as large as in the fan-pressurization test. Significantly, the Delta Q test responded to subtle changes in the leakage configuration near the return register that the fan-pressurization test could not detect. Making use of information on the leakage hole size, as prescribed in the Delta Q Plus procedure, resolved most of the remaining systematic discrepancies between measured and Delta $Q$ leakage values, above the unavoidable random "noise" caused mainly by envelope leakage. 


\section{Acknowledgments}

This work was supported by the Office of Building Technology, State and Community Programs, U.S. Department of Energy. I thank Program Manager Esher Kweller for his continuing encouragement, thoughtful comments, and intellectual contributions across this area of research. I thank Gary Nelson of Energy Conservatory, Inc. (Minneapolis) for supplying the unpowered duct blower used in some of the measurements.

\section{References}

Andrews, J.W. 2002. Impact of Duct Leakage Pressures on the Shape of the Delta $Q$ Curve, BNL-69049. Upton, N.Y.: Brookhaven National Laboratory.

Andrews, J.W. 2000. Measurement Uncertainties in the Delta Q Test for Duct Leakage. BNL-67894. Upton, N.Y.: Brookhaven National Laboratory.

ASHRAE 2001. Method of Test for Determining the Design and Seasonal Efficiencies of Residential Thermal Distribution Systems. Standard 152P. Atlanta, Ga.: American Society of Heating, Refrigerating, and Air-Conditioning Engineers.

Cummings, J.B., C.R. Withers, Jr., and N. Moyer. 2000. Evaluation of Duct Leakage Estimation Procedures in ASHRAE Standard 152P. ASHRAE Transactions 106(2). Atlanta, Ga.: American Society of Heating, Refrigerating, and Air-Conditioning Engineers.

Francisco, P.W. and L. Palmiter 2000a. Performance of Duct Leakage Measurement Techniques in Estimating Duct Efficiency: Comparison to Measured Results. Proc. ACEEE 2000 Summer Study on Energy Efficiency in Buildings. Washington, D.C.: American Council for an Energy Efficient Economy.

Francisco, P.W. and L. Palmiter 2000b. Field Validation of Standard 152P. ASHRAE Transactions 106(2). Atlanta, Ga.: American Society of Heating, Refrigerating, and Air-Conditioning Engineers.

Francisco, P.W. and L. Palmiter 2001. Improved Ways to Measure Residential Duct Leakage, Final Report, ASHRAE Project 1164-RP. Atlanta, Ga.: American Society of Heating, Refrigerating, and Air-Conditioning Engineers.

Walker, I.S., M.H. Sherman, J. Wempen, D. Wang, J.A. McWilliams, and D.J. Dickerhoff. 2001. Development of a New Duct Leakage Test: Delta Q. LBNL-47305. Berkeley, Calif:: Lawrence Berkeley National Laboratory. 